\title{
Novel multi-device unified powerquality conditioner for powerquality improvement
}

\author{
Naarisetti Srinivasa Rao, Pulipaka Venkata Ramana Rao \\ Department of Electrical and Electronics Engineering, Acharya Nagarjuna University, Guntur, India
}

\begin{tabular}{l}
\hline Article Info \\
\hline Article history: \\
Received Jul 24, 2021 \\
Revised Jan 25, 2022 \\
Accepted Feb 1, 2022 \\
\hline
\end{tabular}

Keywords:

Diode-clamped MLI

Multi-carried Based PWM

Multi-device UPQC

Power-quality

Universal voltage-current

Reference controller

\begin{abstract}
This paper describes the customizable multi-device unified power-quality conditioner (MD-UPQC) is designed especially for multi-feeder distribution networks. The proposed MD-UPQC can exchange the power between the multi-feeders and proficiently mitigates all voltage-current associated power-quality problems, make sure to maintain balanced power-flow to consumers. At recent days, various manufacturers recommend the provision of multilevel inverters in mid-range customized compensation devices with desirable control schemes. In distinct, the 5-level diode-clamped multi-level inverter (DCMLI) is best suited for MD-UPQC over traditional 3-level voltage source inverter (VSI) topology for attaining enhanced features. In this paper, MD-UPQC has been proposed with three 5-level DCMLI modules interfaced as back-to-back with a common direct current (DC) capacitor. The simplified phase-dispositional modulation technique is easily assembled with proposed universal voltage-current reference controller for significant functioning of DCMLI-MDUPQC device. The operation and performance of proposed model and its control scheme is evaluated with MATLAB/Simulink computational tool, simulation results are presented.
\end{abstract}

This is an open access article under the CC BY-SA license.

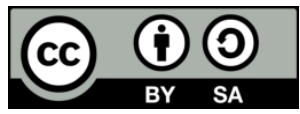

\section{Corresponding Author:}

Naarisetti Srinivasa Rao

Department of Electrical and Electronics Engineering, Acharya Nagarjuna University

Guntur, Andhra Pradesh, India

Email: nsrinivasarao.eee@gmail.com

\section{INTRODUCTION}

The power-quality (PQ) in multi-feeder distribution networks has been crucially proliferated, affecting the loads connected at common feeding point of distribution network due to several deviations and distortions [1]. The increased use of non-linear power-electronic converters, short-circuits, switching of massive loads and electric motors takes-place in secondary distribution networks are the frequent examples causing the PQ distortions [2]. It initiates the injection of harmonic currents, reactive-power extraction, load unbalancing, and poor power-factor. Moreover, the effect of voltage-quality initiates the voltage harmonics, voltage sag-swells, voltage unbalance and voltage deviations which imply the power-pollution at common-feeding point of distribution network [3]. These critical loads are connected to a network with unfortunate PQ then customized flexible alternate current transmission system (FACTS) devices should be introduced to compensate these deficits [4], [5].

The multi-feeder customized FACTS devices are categorized as many groups based on definite PQ problems and its affects such as interline dynamic-voltage restorer [6], interline power-flow controller [7], and interline-unified power-quality controller [8], so on. Particularly, multi-device unified power-quality conditioner (MD-UPQC) is designed especially for PQ enrichment in multi-feeder distribution systems. It can exchange power between multi-feeders and proficiently mitigates both voltage-current associated PQ problems and make 
sure to maintain quality power in multi-feeder distribution systems. The structure of the MD-UPQC device in multi-feeder distribution network is most likely presented in [9]; substantially it is designed with multiple voltage source inverters (VSIs) connected as back-to-back form like series-shunt, shunt-shunt and shunt-series manner between the feeders through common DC-link point.

Mukassir et al. proposed the novel design of multi-converter UPQC for PQ improvement in multifeeder distribution network using multiple VSIs as shunt-series form connected through an equal DC capacitor in [10]. Rao and Rao [11] explored the multi-feeder universal compensation device for mitigating of both load voltage and source current related PQ problems. Moreover, it provides power transfer between the feeders during sudden interruptions by using multi-feeder unified power-quality controller is developed through multi-VSIs devices in [11]. Yadav et al. [12] explored the new trend multi-converter UPQC in multibus distribution network for PQ conditioning for maintaining load current and supply voltage as balanced nature. The MC-UPQC is developed with the help of shunt-series connected VSIs through common DC-point capacitor in [12].

The major problems highlighted in traditional three-level VSIs in customized-compensation is proposed in [10]-[12] have limited developments due to common-mode voltage and reverse voltage blocking capability of switches. Also, its di/dt and dv/dt introduces the more electro-magnetic interference (EMI) loss to entire system. To overcome limitations in traditional three-level VSIs by introducing multilevel inverter (MLI) technology. It is the most relevant technology employed for high-power medium-voltage distribution system, also used in electric-vehicle (EVs), distribution generation (DGs), variable speed drives (VSDs) applications [13].

Multilevel inverters are grown, explored and recommended at high rate in recent past, it is even under development and research on MLI based customized FACTS devices. A multilevel inverter produce AC staircase output voltage which is close to the sinusoidal wave-shape by using various switching devices connected to the input DC source. The well-recognized MLI topologies are cascaded H-bridge MLI, flyingcapacitor MLI and diode-clamped MLI topologies [14]-[16]. Among these, the single DC sourced diodeclamped multilevel inverter (DC-MLI) is best suited and incorporated in MD-UPQC device. It is operated through multi-carrier based pulse-width modulation (MCB-PWM) technique with significant control objective [17].

The symmetrical instantaneous control theory (SICT) [18], instantaneous real-power control theory (IRP) [19], and synchronous reference control theory (ID-IQ) [20] are prominent control objectives explored in [21]. The above control objectives are fated-out due to complex dual-transformations, more mathematical analysis and high delayed signals. The major objective of this work is proposing a new universal voltagecurrent reference (UVCR) control objective for generation of reference current/voltage signals to DCMLIMDUPQC device. The proposed UVCR control scheme has been developed with simple mathematical functions, no need of any transformations, low delay and produce fundamental switching frequency in reference voltage and current sequence. The operation of DCMLI-MDUPQC device with proposed UVCR control objective is designed and verified through MATLAB/Simulink computational tool, Simulink results are described in detail.

\section{PROPOSED DCMLI-MDUPQC METHOD}

The schematic model of 5-level DCMLI structure is depicted in Figure 1. In distinct, the proposed 5level diode-clamped multi-level inverter (DCMLI) is best suited over traditional 3-level VSI topology for PQ enhancement [22]. The proposed MD-UPQC is designed with three 5-level DCMLI modules interfaced as back-to-back with a common DC capacitor. It includes, MLI-1, MLI-2 are integrated as shunt-series to feeder-2 and MLI-3 is integrated as series to feeder-1 via 1:1 linear design transformers and filter units. The incorporation of DCMLI in MD-UPQC device is good opportunity for getting enhanced compensation features over the traditional VSI device, and technically accepted for any compensation structure [23]-[25].

It consists, 2(N-1) switches named as upper and lower unit in a single-phase defined as $\mathrm{S}_{1 \mathrm{a}} / \mathrm{S}_{1 \mathrm{a}}$ '; $\mathrm{S}_{2 \mathrm{a}} / \mathrm{S}_{2 \mathrm{a}^{\prime}} ; \mathrm{S}_{3 \mathrm{a}} / \mathrm{S}_{3 \mathrm{a}^{\prime}} ; \mathrm{S}_{4 \mathrm{a}} / \mathrm{S}_{4 \mathrm{a}^{\prime}}$, for appropriate current flow $(\mathrm{N}-1)^{*}(\mathrm{~N}-2)$ clamping diodes are required defined as $\mathrm{D}_{1 \mathrm{a}} / \mathrm{D}_{1 \mathrm{a}}{ }^{\prime} ; \mathrm{D}_{2 \mathrm{a}} / \mathrm{D}_{2 \mathrm{a}} \mathrm{a}^{\prime} ; \mathrm{D}_{3 \mathrm{a}} / \mathrm{D}_{3 \mathrm{a}} \mathrm{a}^{\prime}$, respectively. Mostly, (N-1) DC capacitors are required defined as $\mathrm{C}_{1 \mathrm{a}}, \mathrm{C}_{2 \mathrm{a}}$, in upper unit and $\mathrm{C}_{3 \mathrm{a}}, \mathrm{C}_{4 \mathrm{a}}$ in lower unit connected to a neutral point $\left(\mathrm{N}_{\mathrm{ca}}\right)$ to maintain common DC voltage as $\mathrm{V}_{\mathrm{dc.L}}$. The schematic model of proposed DCMLI-MDUPQC is depicted in Figure 2. The synthetization of various switching actions produce the 5-level output voltage at load terminals to drive the MD-UPQC with voltage levels of $\mathrm{V}_{\mathrm{dca}} / 4 ; \mathrm{V}_{\mathrm{dca}} / 2 ; 0 \mathrm{~V}_{\mathrm{dca}} ;-\mathrm{V}_{\mathrm{dca}} / 4$ and $-\mathrm{V}_{\mathrm{dca}} / 2$, respectively. The switching arrangement of 5-level DCMLI structure is represented in Table 1. This switching action shows, "1" represents the conducted switches and "0" represents the non-conducted switches in a 5-level DCMLI switching arrangement. 


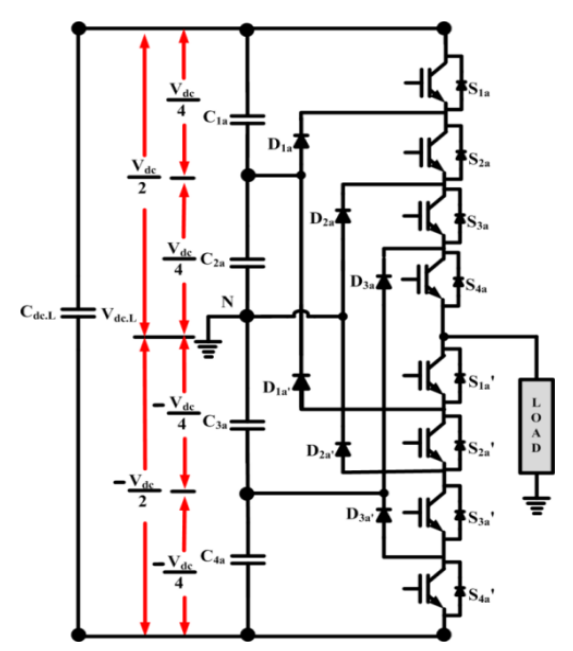

Figure 1. Model of 5-level DCMLI structure

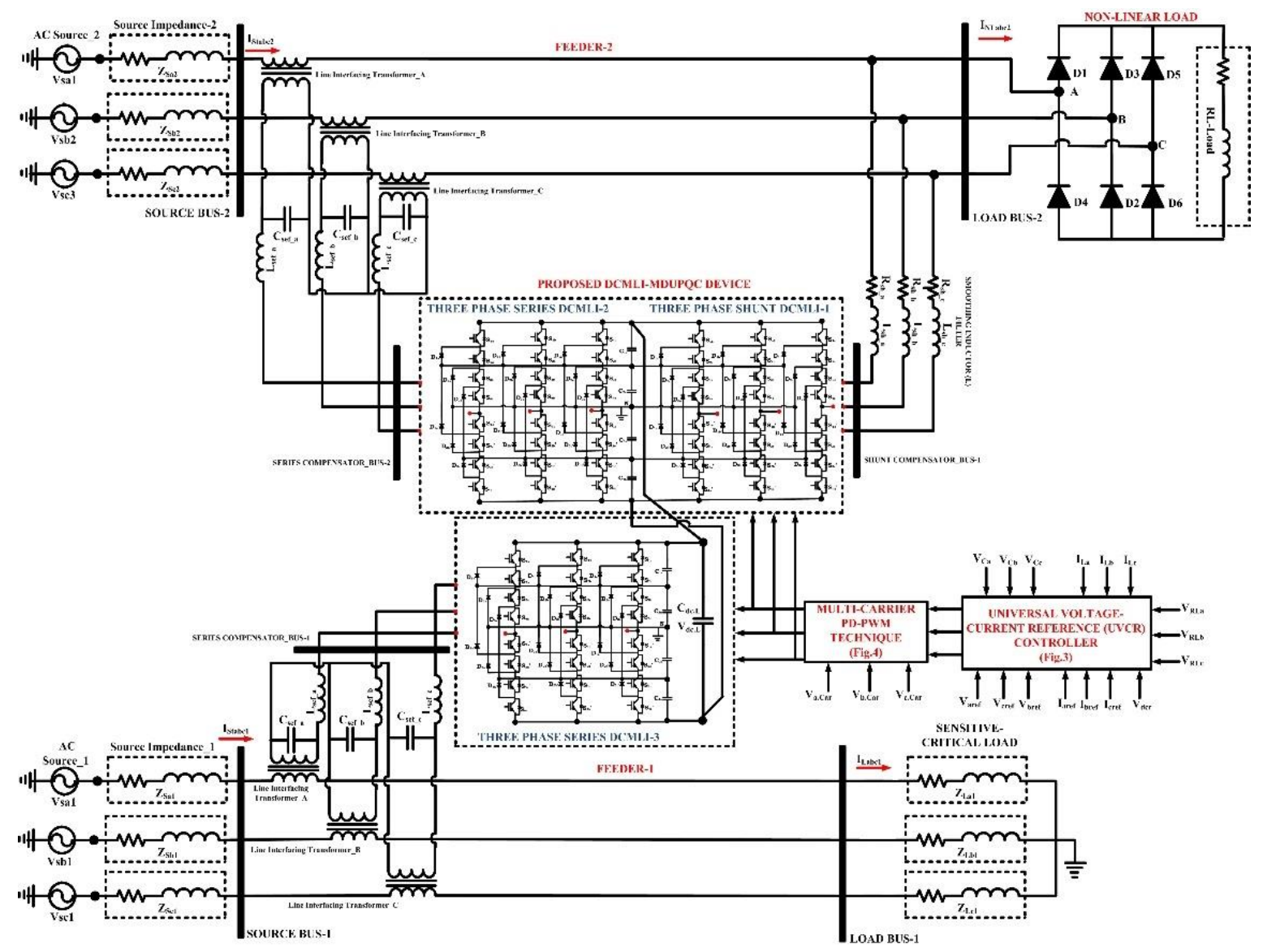

Figure 2. Schematic model of proposed DCMLI-MDUPQC

Table 1. Switching arrangement of 5-level DCMLI structure

\begin{tabular}{ccccccccc}
\hline \multirow{2}{*}{ DCMLI Voltage $(\mathrm{Vo})$} & \multicolumn{8}{c}{ Switching Arrangement } \\
\hline $\mathrm{V}_{\mathrm{dca}} / 4$ & 0 & 1 & 1 & 1 & 1 & 0 & 0 & 0 \\
$\mathrm{~V}_{\mathrm{dca}} / 2$ & 1 & 1 & 1 & 1 & 0 & 0 & 0 & 0 \\
$0 \mathrm{~V}_{\mathrm{dca}}$ & 0 & 0 & 1 & 1 & 1 & 1 & 0 & 0 \\
$-\mathrm{V}_{\mathrm{dca}} / 4$ & 0 & 0 & 0 & 1 & 1 & 1 & 1 & 0 \\
$-\mathrm{V}_{\mathrm{dca}} / 2$ & 0 & 0 & 0 & 0 & 1 & 1 & 1 & 1 \\
\hline
\end{tabular}




\section{PROPOSED UVCR CONTROLLER}

The switching action of DCMLI of MD-UPQC device is controlled by using suitable switching states with extraction of reference voltage-current signals via proposed UVCR control scheme. The proposed UVCR scheme doesn't requires any phase transformation techniques and producing the reference signals with a low computational delay over the classical abc-dq transform extraction schemes. It delivers reference signals by sensing load voltage which develops unit-vector signals through pre-synchronize angle $\left(\theta_{\mathrm{s}}\right)$ received from discrete phase-lock loop (D-PLL). Schematic model of proposed UVCR control scheme for DCMLI based MDUPQC device is depicted in Figure 3. The unit-vector module composes the non-complex vector signals which are described in (1) \& (2) as, the sensed load voltage is represented as (1).

$$
\begin{aligned}
& V_{L . a}=V_{s t . a} \sin \theta s \\
& V_{L . b}=V_{s t . b} \sin (\theta s-2 \pi / 3) \\
& V_{L . c}=V_{s t . c} \sin (\theta s+2 \pi / 3)
\end{aligned}
$$

The non-complex unit-vector signal is represented as (2).

$$
V_{s t . a b c}=\left\{\frac{2}{3}\left(V_{L . a}^{2}+V_{L . b}^{2}+V_{L . c}^{2}\right)\right\}^{1 / 2}
$$

The extracted non-complex vector signals are defined as in-phase quadrature components represented as (3).

$$
\begin{aligned}
& U V_{\text {st.a }}=\frac{V_{L . a}}{V_{\text {st. } a b c}}=\sin \theta s \\
& U V_{\text {st. }}=\frac{V_{L . b}}{V_{\text {st.abc }}}=\sin (\theta s-2 \pi / 3) \\
& U V_{\text {st.c }}=\frac{V_{L . c}}{V_{\text {st.abc }}}=\sin (\theta s+2 \pi / 3)
\end{aligned}
$$

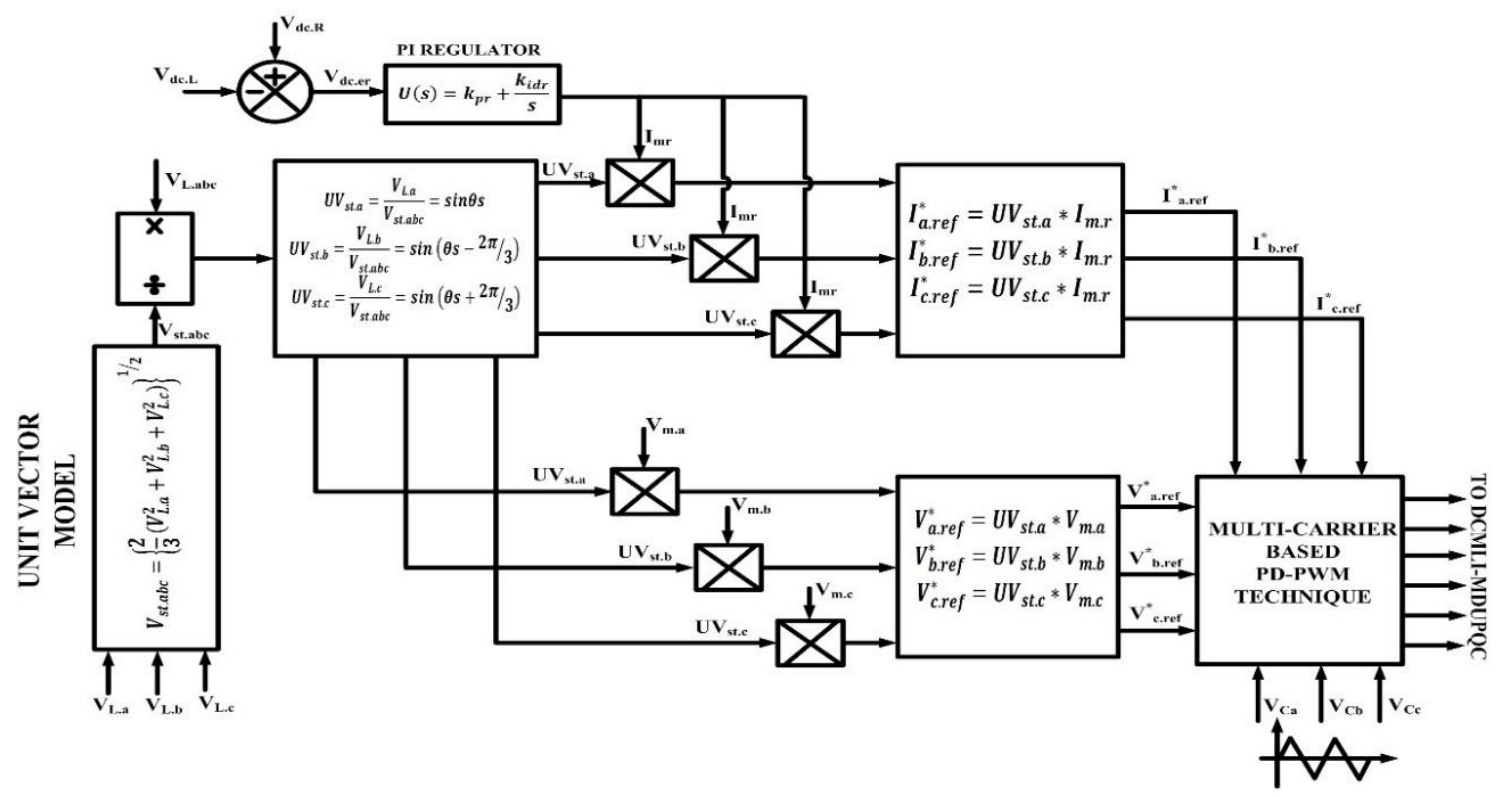

Figure 3. Schematic model of proposed UVCR control scheme for DCMLI based MDUPQC device

The extracted non-complex vector signals $\left(U V_{s t . a b c}\right)$ is propagated with measured voltage signal $\left(V_{m . a b c}\right)$ for extracting reference voltage signal $\left(V_{a b c . r e f}^{*}\right)$ to series MLI-2 and series MLI-3 of DCMLI of MD-UPQC device is described as (4).

$$
\begin{aligned}
& V_{a . r e f}^{*}=U V_{\text {st.a }} * V_{m . a} \\
& V_{b . r e f}^{*}=U V_{\text {st.b }} * V_{m . b} \\
& V_{c . r e f}^{*}=U V_{\text {st.c }} * V_{m . c}
\end{aligned}
$$


The extracted non-complex vector signals $\left(U V_{s t . a b c}\right)$ is propagated with measured current signal $\left(I_{m . r}\right)$ for extracting reference current signal ( $\left.I_{a b c . r e f}^{*}\right)$ to shunt MLI-1 of DCMLI of MD-UPQC device is described as (5).

$$
\begin{aligned}
& I_{\text {a.ref }}^{*}=U V_{\text {st.a }} * I_{m . r} \\
& I_{\text {b.ref }}^{*}=U V_{\text {st. } b} * I_{m . r} \\
& I_{\text {c.ref }}^{*}=U V_{\text {st.c }} * I_{m . r}
\end{aligned}
$$

The reference current signal $\left(I_{m . r}\right)$ is received from feed-forward DC voltage controller which reduces the loss components and eliminate the circulation currents in input DC capacitors of DCMLI. Also, it maintains DC voltage as constant by comparing the measured DC voltage $\left(\mathrm{V}_{\mathrm{dc} . \mathrm{L}}\right)$ and reference $\mathrm{DC}$ voltage $\left(\mathrm{V}_{\mathrm{dc} . \mathrm{R}}\right)$ and creates error signals. These error signals are counteracted with proportional-integral (PI) regulator and establish the active reference current signals described as (6) and (7).

$$
\begin{aligned}
& V_{d c . e r}=V_{d c . R}^{*}-V_{d c . L} \\
& I_{m . r}=K_{p r} *\left(V_{d c . e r(k)}-V_{d c . e r(k-1)}\right)+K_{i r} *\left(V_{d c . e r(k)}\right)
\end{aligned}
$$

The proposed UVCR control scheme extracts reference voltage-current signals and the actual signals are propagated with multi-carrier based pulse-width modulation (MCB-PWM) technique for generation of feasible switching pattern to DCMLI-MDUPQC device. Several MCB-PWM techniques are available for MLI structures and classification is relied on shifting of carrier position such as phaseopposition disposition (POD), phase-disposition (PD) and alternate phase-opposition disposition (APOD), respectively. The PD technique is considered here and $\mathrm{N}-1$ carriers are required for generation of $\mathrm{N}$ number of voltage levels; 4 carriers are required for generation of 5-level output voltage. The representation of multicarrier based phase-disposition pulse-width modulation (PD-PWM) technique is depicted in Figure 4.

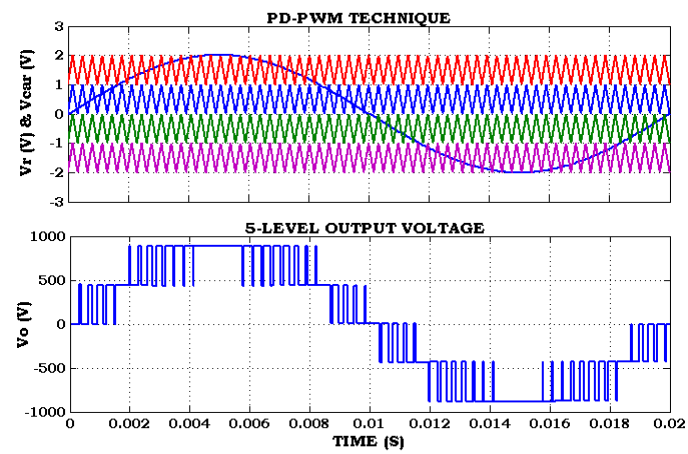

Figure 4. Multi-carrier based PD-PWM technique

\section{RESULTS \& DISCUSSION}

The operation of proposed model and control scheme are discussed, the performance of proposed

\begin{tabular}{|c|c|c|c|}
\hline \multirow{2}{*}{ S. No } & \multirow{2}{*}{ Parameters } & \multicolumn{2}{|c|}{ Values } \\
\hline & & Feeder-2 & Feeder-1 \\
\hline 1 & Source Terminal Voltage $\left(\mathrm{V}_{\mathrm{rms}}\right)$ & \multicolumn{2}{|c|}{$\mathrm{V}_{\mathrm{sf1}}-\mathrm{V}_{\mathrm{sf2}-}-415 \mathrm{Vrms}, 50 \mathrm{~Hz}$} \\
\hline & & Non-Linear PE Load in Feeder-2 & Sensitive Load in Feeder-1 \\
\hline & & $\mathrm{V}_{\mathrm{L} .2}=415 \mathrm{Vrms}, 50 \mathrm{~Hz}$ & $\mathrm{~V}_{\mathrm{L} .1}=415 \mathrm{Vrms}, 50 \mathrm{~Hz}$ \\
\hline 2 & Load Specifications & $\mathrm{R}_{\mathrm{L} 1}=30 \Omega, \mathrm{L}_{\mathrm{L} 1}-20 \mathrm{mH}$ & $\begin{array}{l}\mathrm{P}_{\text {Load.1 }}=10 \mathrm{KW}, \\
\mathrm{Q}_{\text {Load.1. }}=5 \mathrm{KVar}\end{array}$ \\
\hline 3 & Feeder Impedance & \multicolumn{2}{|c|}{$\mathrm{R}_{\mathrm{sf}}=0.15 \Omega, \mathrm{L}_{\mathrm{sf}}-0.9 \mathrm{mH}$} \\
\hline 4 & 1:1 Line Connected Transformer & \multicolumn{2}{|c|}{$415 \mathrm{~V}, 5 \mathrm{KVA}$, Linear type, $10 \%$ of Leakage Reactance } \\
\hline 5 & Carrier Switching Frequency & \multicolumn{2}{|c|}{ Fc-3050Hz, MI-1 } \\
\hline 6 & Shunt-MLI Line Compensated Filter & \multicolumn{2}{|c|}{$\mathrm{R}_{\mathrm{sh} .2}=0.001 \Omega, \mathrm{L}_{\mathrm{sh} .2}-10 \mathrm{mH}$} \\
\hline 7 & Series-MLI Line Compensated Filter & \multicolumn{2}{|c|}{$\mathrm{L}_{\mathrm{se} .12-} 3 \mathrm{mH}, \mathrm{C}_{\mathrm{se} .12-}-100 \mu \mathrm{F}$} \\
\hline 8 & Common DC-Link Capacitor & \multicolumn{2}{|c|}{$\mathrm{C}_{\mathrm{dc} . \mathrm{L}}=1500 \mu \mathrm{F}, \mathrm{V}_{\mathrm{dc} . \mathrm{L}}=880 \mathrm{~V}$} \\
\hline
\end{tabular}
DCMLI-MDUPQC structure is evaluated with MATLAB/Simulink computational tool and simulation results are presented. The system parameters and their values of proposed UVCR controlled DCMLI-MDUPQC device is considered in [18] and represented in Table 2.

Table 2. Proposed system parameters and values

Int J Pow Elec \& Dri Syst, Vol. 13, No. 1, March 2022: 390-400 


\subsection{Compensation of voltage and current associated PQ problems in feeder-2 using proposed UVCR controlled DCMLI-MDUPQC Device}

The simulation results of proposed UVCR controlled shunt MLI-1 of DCMLI-MDUPQC device in feeder-2 for compensation of harmonic currents is depicted in Figures 5 (a)-(d). The three-phase multi-feeder distribution network is used to drive the non-linear diode-bridge rectifier load with a source terminal voltage of $415 \mathrm{Vrms}, 50 \mathrm{~Hz}$ supply. The critical non-linear diode-bridge load creates the harmonic distortions in source current proliferates the other loads connected at common point. These harmonic currents affecting the functioning of other loads and produces high losses, more heat and damaging the feeder specifications is shown in Figure 5 (a). These harmonic currents are mitigated by employing shunt MLI-1 of MD-UPQC operated as in-phase current compensation principle. Also, it regulates the load reactive power, source power factor, and load balancing, maintaining the system specifications as linear, sinusoidal and balanced nature in feeder-2. The total harmonic distortion (THD) value of source terminal current in feeder-2 is measured as $1.47 \%$ is shown in Figure 5 (b), it is complying with IEEE standards and the THD of non-linear rectifier load current in feeder-2 is measured as $30.19 \%$ is shown in Figure 5 (c). Moreover, the source current seems as inphase with thesource terminal voltage which shows the unity power factor in feeder-2 is shown in Figure 5 (d).

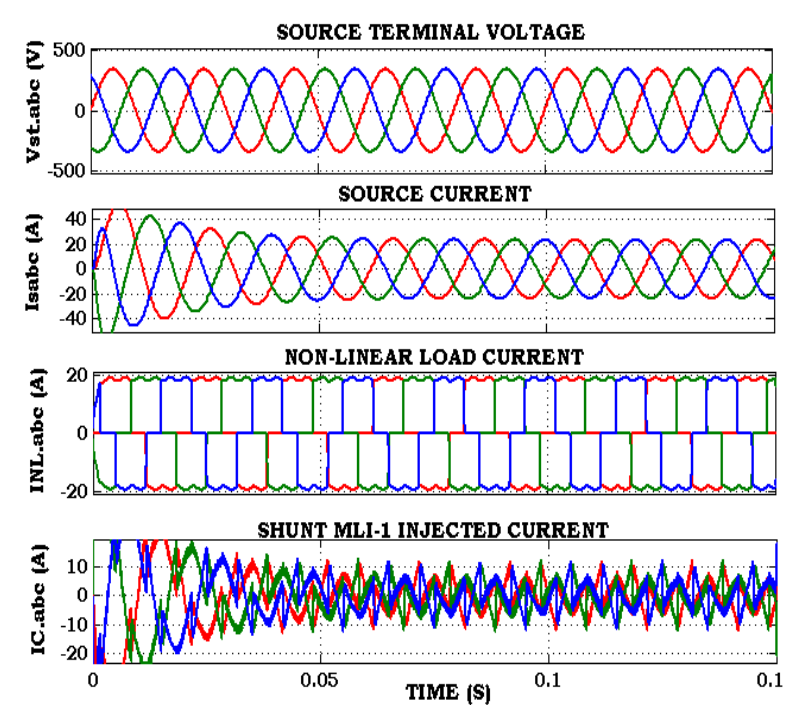

(a)

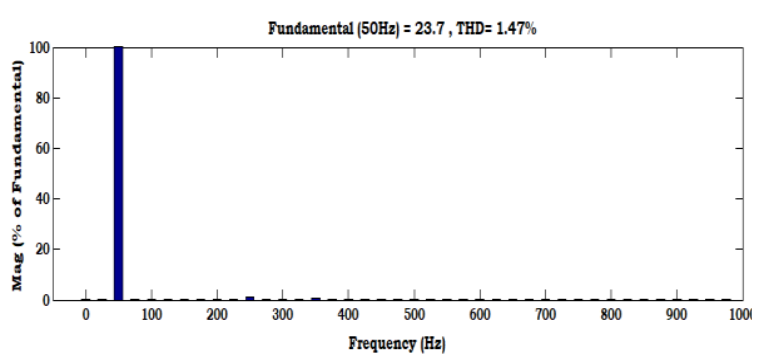

(b)

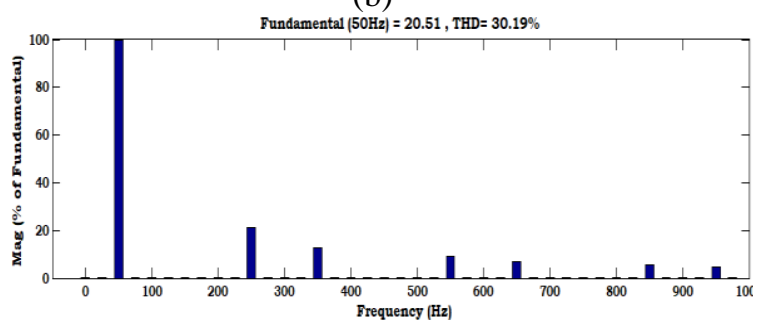

(c)

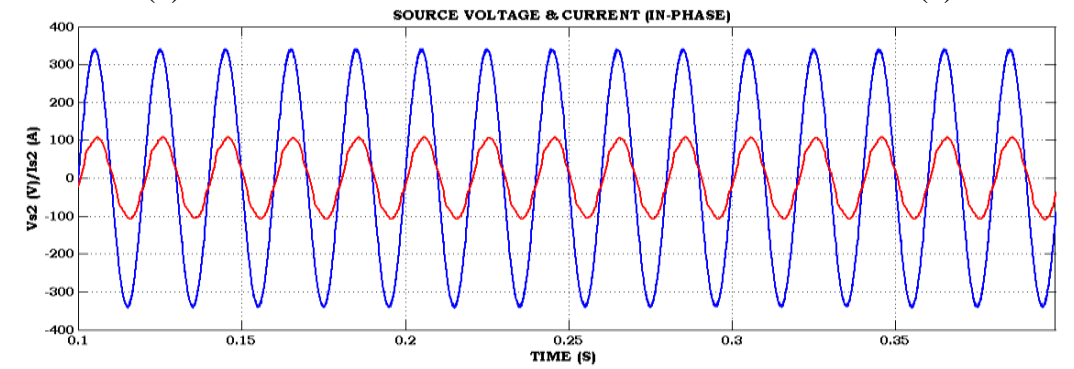

(d)

Figure 5. Simulation results shows (a) proposed UVCR controlled shunt MLI-1 of DCMLI-MDUPQC device in feeder-2, (b) THD of source current in feeder-2, (c) THD of non-linear PE load current in feeder-2 and (d) source current in-phase with source voltage

The simulation results of proposed UVCR controlled series MLI-2 of DCMLI-MDUPQC device infeeder-2 for compensation of voltage harmonics, voltage sags-swells, is depicted in Figures 6 (a)-(c). During pre-sag condition source terminal voltage is retained as constant, then voltage-sag is occurred at a time instant of $0.15 \mathrm{sec}<\mathrm{t}<0.25 \mathrm{sec}$ and the value of source terminal voltage is decreased to $170 \mathrm{~V}$. But the load voltage is unaffected and retained as constant of $340 \mathrm{~V}$, due to presence of series MLI- 2 in feeder- 2 . It compensates voltage sag problem and inject required voltage as $170 \mathrm{~V}$ to drive the non-linear load as balanced nature. During pre-swell condition source terminal voltage is retained as constant, then voltageswell is occurred at a time instant of $0.35 \mathrm{sec}<\mathrm{t}<0.45 \mathrm{sec}$ and the value of source terminal voltage is 
increased to $510 \mathrm{~V}$. But the load voltage is unaffected and retained as constant of $340 \mathrm{~V}$, due to presence of series MLI-2 in feeder-2. It compensates voltage swell problem and extracts required voltage as $170 \mathrm{~V}$ to drive the non-linear load as balanced nature. The terminal voltage consists of non-sinusoidal voltage harmonics occurred between $0.5 \mathrm{sec}<\mathrm{t}<0.6 \mathrm{sec}$, affecting the common-point or consumer end-point.

These harmonic voltages affecting the functioning of other loads and produces high losses, more heat and damaging the feeder specifications. These harmonic voltages are mitigated by employing series MLI-2 of MD-UPQC operated as in-phase voltage compensation principle. Also, it regulates the load reactive power, source power factor, and load balancing, maintaining the system specifications as linear, sinusoidal and balanced nature in feeder-2 is shown in Figure 6 (a). The THD value of non-linear load voltage in feeder- 2 is measured as $0.5 \%$ is shown in Figure $6(\mathrm{~b})$, it is complying with IEEE standards and the THD value of source terminal voltage in feeder- 2 during voltage harmonics is measured as $20.62 \%$ is shown in Figure 6 (c).
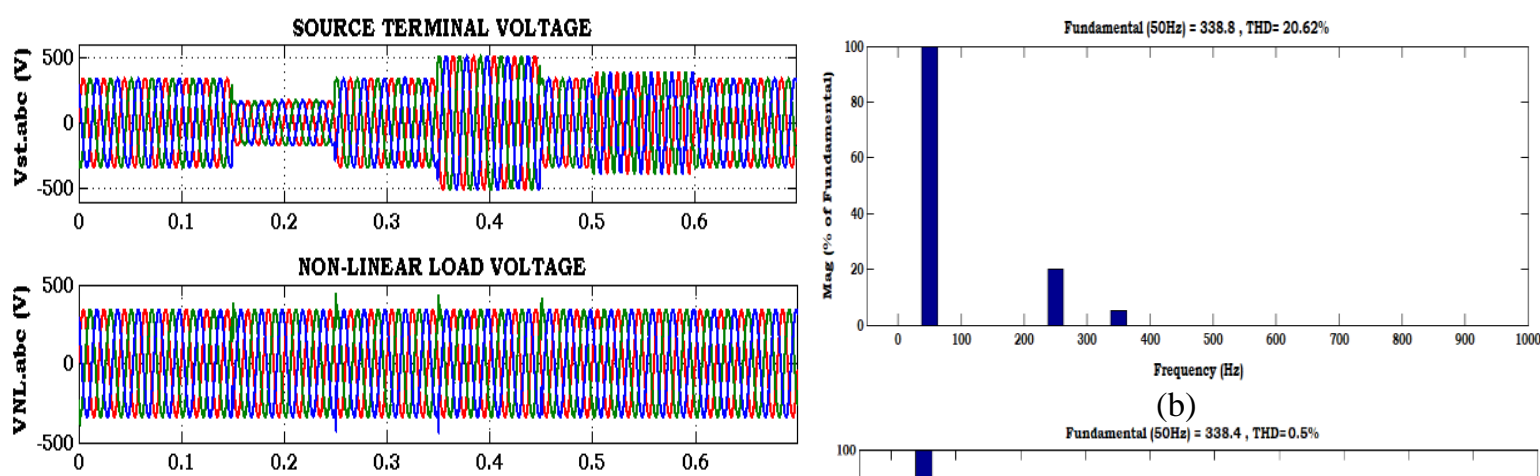

(b)

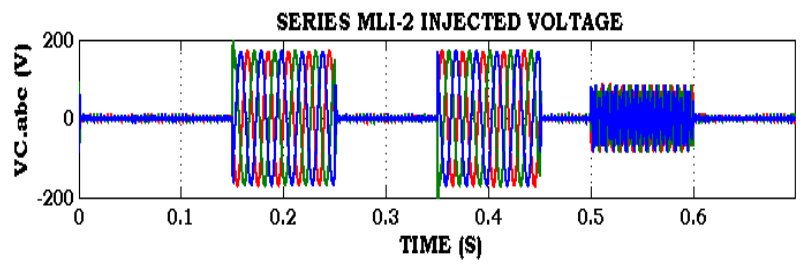

(a)

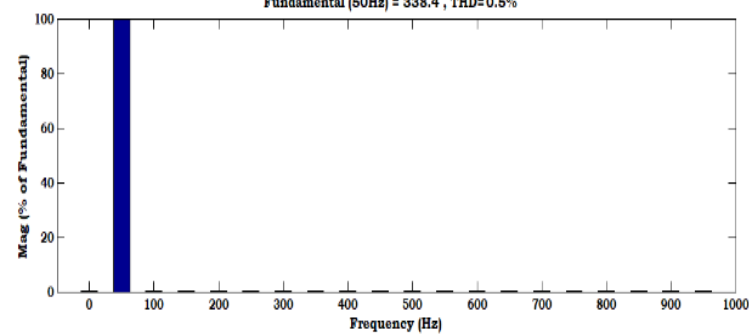

(c)

Figure 6. Simulation results shows (a) proposed UVCR controlled series MLI-2 of DCMLI-MDUPQC device in Feeder-2, (b) THD of critical non-linear load voltage, and (c) THD of source terminal voltage

The proposed series MLI-2 of MD-UPQC compensates all voltage problems and maintains load voltage as sinusoidal and fundamental nature to drive the non-linear load as balanced condition. The THD comparison of source \& load voltages in feeder-2 of traditional 3-level VSI \& proposed 5-level DCMLI based MD-UPQC device is illustrated in Table 3. The THD comparison of source \& load currents in feeder- 2 of traditional 3-level VSI \& proposed 5-level DCMLI based MD-UPQC device is illustrated in Table 4. The active and reactive powers of source, injected compensator and critical load of DCMLI-MDUPQC Device in Feeder-2 are depicted in Figure 7. The calculated power values of source, compensator and load in Feeder-2 of proposed 5-level DCMLI-MD UPQC device under voltage associated PQ problems is illustrated in Table 5.

Table 3. THD comparison of source \& load voltages in feeder-2 of traditional 3-level VSI \&proposed 5-level DCMLI based MD-UPQC device

\begin{tabular}{|c|c|c|c|c|c|c|c|c|c|}
\hline \multirow[t]{2}{*}{ THD (\%) } & \multicolumn{3}{|c|}{ Source Voltage } & \multicolumn{3}{|c|}{ Load Voltage } & \multicolumn{3}{|c|}{ Output Voltage } \\
\hline & $\mathrm{a}$ & $\mathrm{b}$ & $\mathrm{c}$ & $\mathrm{a}$ & $\mathrm{b}$ & c & $\mathrm{a}$ & $\mathrm{b}$ & c \\
\hline $\begin{array}{c}\text { Traditional 3-Level VSI Based MD-UPQC } \\
{[10]}\end{array}$ & $20.62 \%$ & $20.62 \%$ & $20.62 \%$ & $1.72 \%$ & $1.63 \%$ & $1.71 \%$ & $91.7 \%$ & $89.03 \%$ & $90.3 \%$ \\
\hline $\begin{array}{c}\text { Proposed 5-Level DCMLI Based MD- } \\
\text { UPQC }\end{array}$ & $20.62 \%$ & $20.62 \%$ & $20.62 \%$ & $0.89 \%$ & $0.91 \%$ & $0.83 \%$ & $27.5 \%$ & $27.3 \%$ & $27.3 \%$ \\
\hline
\end{tabular}


Table 4. THD comparison of source \& load currents in feeder-2 of traditional 3-level VSI \& proposed 5-level DCMLI based MD-UPQC device

\begin{tabular}{ccccccc}
\hline THD (\%) & \multicolumn{3}{c}{ Source Current } & \multicolumn{3}{c}{ Load Current } \\
& $\mathrm{a}$ & $\mathrm{b}$ & $\mathrm{c}$ & $\mathrm{a}$ & $\mathrm{b}$ & $\mathrm{c}$ \\
\hline Traditional 3-Level VSI Based MD-UPQC [10] & $5.12 \%$ & $5.09 \%$ & $5.48 \%$ & $30.14 \%$ & $30.04 \%$ & $30.06 \%$ \\
Proposed 5-Level DCMLI Based MD-UPQC & $1.47 \%$ & $1.60 \%$ & $1.58 \%$ & $30.19 \%$ & $29.97 \%$ & $30.11 \%$ \\
\hline
\end{tabular}
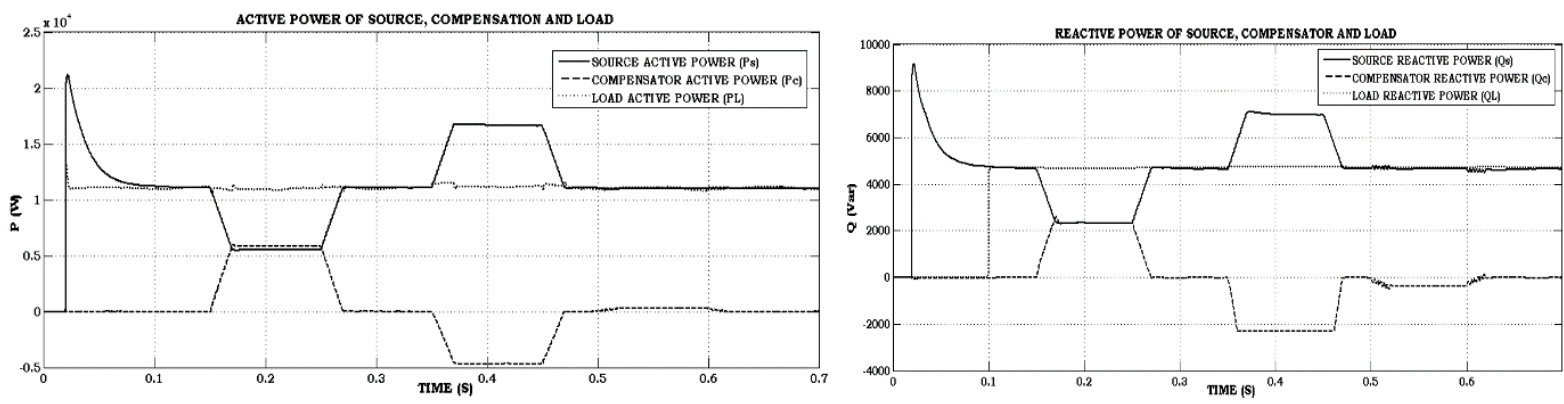

Figure 7. Active and reactive powers of source, injected compensator, critical load of DCMLI-MDUPQC device in feeder-2

Table 5. Power calculation of source, compensator and load values in feeder-2 of proposed 5-level DCMLI Based MD-UPQC device under voltage associated PQ problems

\begin{tabular}{|c|c|c|c|c|c|c|c|c|c|}
\hline \multirow[t]{2}{*}{ Power } & \multicolumn{3}{|c|}{ Pre-Condition } & \multicolumn{3}{|c|}{ Voltage-Sag } & \multicolumn{3}{|c|}{ Voltage-Swell } \\
\hline & Source & Inject & Load & Source & Inject & Load & Source & Extract & Load \\
\hline Active Por & $11.1 \mathrm{KW}$ & $0 \mathrm{KW}$ & $11.05 \mathrm{KW}$ & $5.5 \mathrm{KW}$ & $5.55 \mathrm{KW}$ & $11.05 \mathrm{KW}$ & $15.95 \mathrm{KW}$ & $4.9 \mathrm{KW}$ & $11.05 \mathrm{KW}$ \\
\hline Reactive Power (Var) & 4.7 KVar & $0 \mathrm{KVar}$ & 4.7 KVar & $2.4 \mathrm{KVar}$ & $2.3 \mathrm{KVar}$ & 4.7 KVar & $7 \mathrm{KVar}$ & $2.3 \mathrm{KVar}$ & 4.7 KVar \\
\hline
\end{tabular}

\subsection{Compensation of voltage associated PQ problems in feeder-1 using proposed UVCR controlled DCMLI-MDUPQC device}

The simulation results of proposed UVCR controlled series MLI-3 of DCMLI-MDUPQC device in feeder-1 for compensation of voltage harmonics, voltage sags-swells, and voltage deviations is depicted in Figures 8 (a)-(c). The terminal voltage consists of non-sinusoidal voltage harmonics, voltage-sag-swells and voltage deviation, affecting the common-point or consumer end-point. During pre-sag condition source terminal voltage is retained as constant, then voltage-sag is occurred at a time instant of $0.2 \mathrm{sec}<\mathrm{t}<0.3 \mathrm{sec}$ and the value of source terminal voltage is decreased to $170 \mathrm{~V}$. But the load voltage is unaffected and retained as constant of $340 \mathrm{~V}$, due to presence of series MLI-3 in feeder-1. It compensates voltage sag problem and inject required voltage as $170 \mathrm{~V}$ to drive the non-linear load as balanced nature. During pre-swell condition source terminal voltage is retained as constant, then voltage-swell is occurred at a time instant of $0.4 \mathrm{sec}$ $<\mathrm{t}<0.5 \mathrm{sec}$ and the value of source terminal voltage is increased to $510 \mathrm{~V}$. But the load voltage is unaffected and retained as constant of $340 \mathrm{~V}$, due to presence of series MLI-3 in feeder-1. It compensates voltage swell problem and extracts required voltage as $170 \mathrm{~V}$ to drive the non-linear load as balanced nature.

During harmonic condition at a time instant of $0.6 \mathrm{sec}<\mathrm{t}<0.7 \mathrm{sec}$, series MLI-3 in feeder-1 of MDUPQC counteracts the $5^{\text {th }}$ and $7^{\text {th }}$ harmonic and injects the required voltage as in-phase compensation strategy and maintains harmonic-free, sinusoidal and fundamental with a value of $340 \mathrm{~V}$ is shown in Figure 8 (a). The THD value of sensitive load voltage in feeder-1 is measured as $0.89 \%$ is shown in Figure 8 (b) it is complying with IEEE standards and the THD value of source terminal voltage in feeder-1 during voltage harmonics is measured as $20.62 \%$ is shown in Figure 8 (c). The proposed series MLI-3 of MD-UPQC compensates all voltage problems and maintains load voltage as sinusoidal and fundamental nature to drive the sensitive load as balanced condition. During pre-voltage deviation condition source terminal voltage is retained as constant, then voltage-deviations is occurred at a time instant of $0.75 \mathrm{sec}<\mathrm{t}<0.85 \mathrm{sec}$ and the value of source terminal voltage is decreased to $0 \mathrm{~V}$. But the load voltage is unaffected and retained as constant of $340 \mathrm{~V}$, due to presence of series MLI-3 in feeder-1. It compensates voltage deviations problem and inject required voltage as $340 \mathrm{~V}$ to drive the sensitive load as balanced nature. The THD comparison of source, load voltage and VSI output voltages in both feeder-1 and feeder-2 of traditional 3-level VSI \& proposed 5-level DCMLI based MD-UPQC device is illustrated in Table 6. 


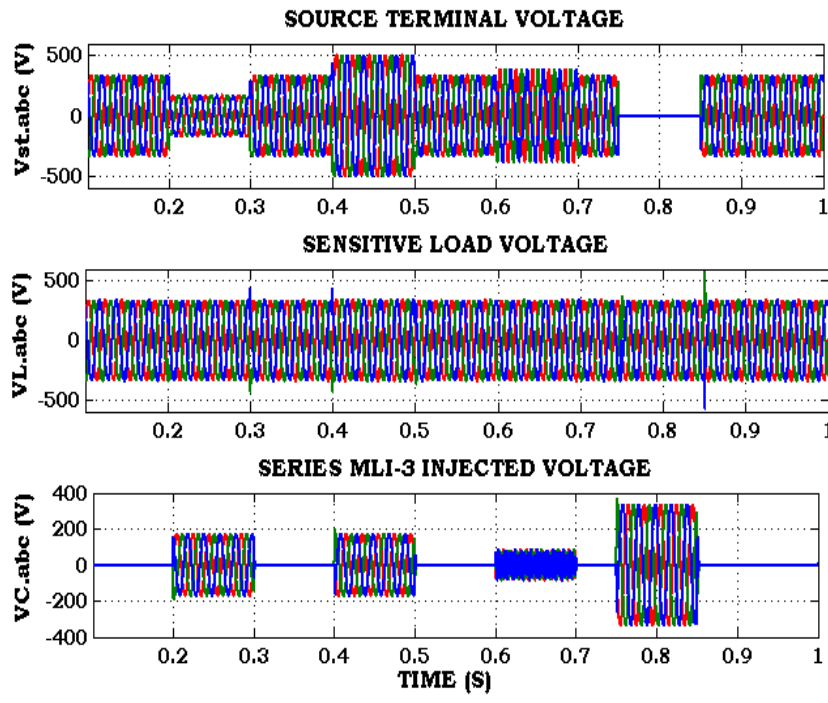

(a)

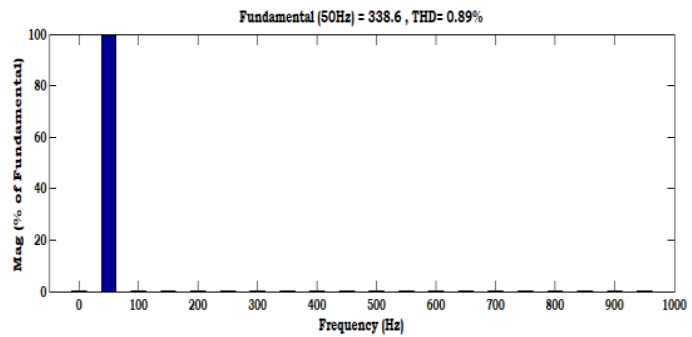

(b)

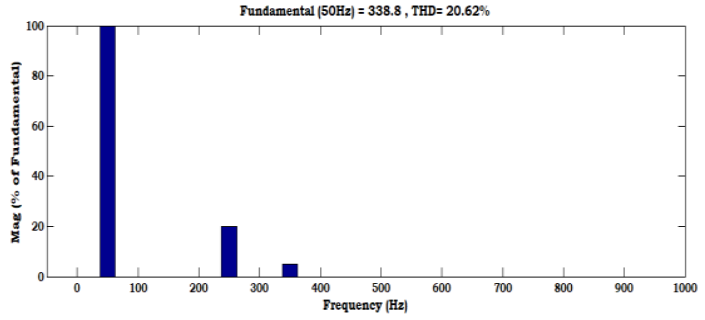

(c)

Figure 8. Simulation results shows (a) proposed UVCR controlled series MLI-3 of DCMLI-MDUPQC device in feeder-1, (b) critical non-linear load voltage in feeder-1 THD values of source terminal voltage, and (c) THD of source terminal voltage

Table 6. THD comparison of source \& load values in feeder-1 of traditional 3-level VSI \&proposed 5-level DCMLI based MD-UPQC device

\begin{tabular}{|c|c|c|c|c|c|c|c|c|c|}
\hline \multirow[t]{2}{*}{ THD (\%) } & \multicolumn{3}{|c|}{ Source Voltage } & \multicolumn{3}{|c|}{ Load Voltage } & \multicolumn{3}{|c|}{ VSI Output Voltage } \\
\hline & $\mathrm{a}$ & $\mathrm{b}$ & $\mathrm{c}$ & $\mathrm{a}$ & $\mathrm{b}$ & c & $\mathrm{a}$ & $\mathrm{b}$ & $\mathrm{c}$ \\
\hline $\begin{array}{l}\text { Traditional 3-Level VSI Based MD-UPQC } \\
{[10]}\end{array}$ & $20.62 \%$ & $20.62 \%$ & $20.62 \%$ & $1.84 \%$ & $1.75 \%$ & $1.89 \%$ & $91.7 \%$ & $89.03 \%$ & $90.3 \%$ \\
\hline $\begin{array}{c}\text { Proposed 5-Level DCMLI Based MD- } \\
\text { UPQC }\end{array}$ & $20.62 \%$ & $20.62 \%$ & $20.62 \%$ & $0.5 \%$ & $0.61 \%$ & $0.58 \%$ & $27.5 \%$ & $27.3 \%$ & $27.3 \%$ \\
\hline
\end{tabular}

The power calculation of source, compensator and load values in feeder-1 of proposed 5-Level DCMLI based MD-UPQC is illustrated in Table 7. The required active, reactive power of feeder-1 is retained as constant by using MD-UPQC device to drive the sensitive load; the voltage across capacitor is retained as constant of $1760 \mathrm{~V}$ through voltage controller as depicted in Figure 9.

Table 7. Power calculation of source, compensator and load values in feeder-1 of proposed 5-level DCMLI based MD-UPQC device under voltage associated PQ problems

\begin{tabular}{|c|c|c|c|c|c|c|c|c|c|c|}
\hline \multirow[t]{2}{*}{ Power } & \multicolumn{2}{|c|}{ Pre-Condition } & \multicolumn{3}{|c|}{ Voltage-Sag } & \multicolumn{3}{|c|}{ Voltage-Swell } & \multicolumn{2}{|c|}{ Voltage Deviations } \\
\hline & Source Inject & Load & rce & Inject & Load & Source & Extract & Load & Source & Inject \\
\hline & & & & & & & & & $0 \mathrm{KW}$ & W 10 \\
\hline Reactive Power (Var) & $5 \mathrm{KV}$ ar $0 \mathrm{KVar}$ & $5 \mathrm{KVar}$ & $.5 \mathrm{KVar}$ & $2.5 \mathrm{KVar}$ & $5 \mathrm{KVar}$ & $7.5 \mathrm{KVar}$ & $2.5 \mathrm{KVar}$ & $5 \mathrm{KVar}$ & Var & $5 \mathrm{KV}$ ar $5 \mathrm{KV}$ ar \\
\hline
\end{tabular}

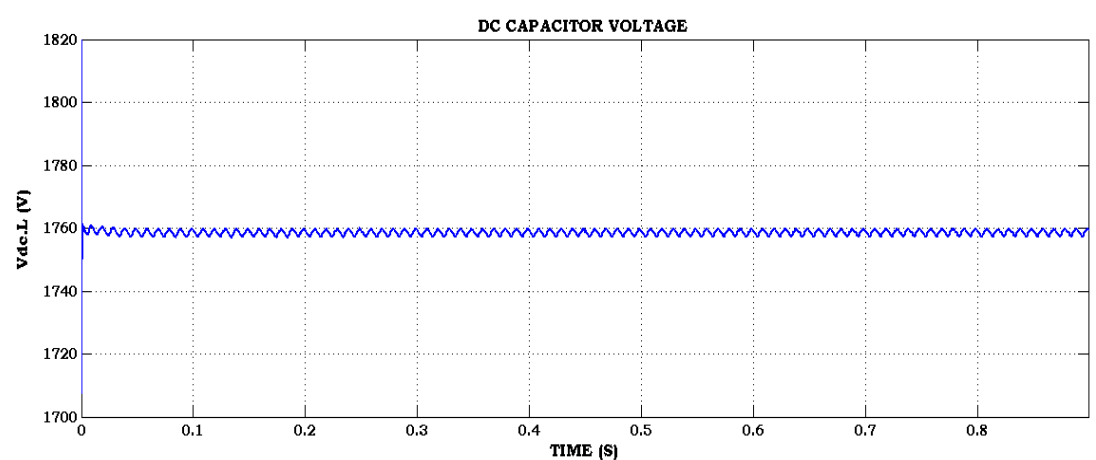

Figure 9. Voltage across common DC capacitor 


\section{CONCLUSION}

The capability of proposed DCMLI topology of MD-UPQC relies on ability of maximum injected current and voltages during particular PQ problem and the required power that can be delivered to load during the both voltage and current associated PQ problems. The proposed 5-level DCMLI topology reduces the common-mode voltage, reverse-voltage blocking capability, low dv/dt and di/dt stress, low EMI loss and maximizing the compensation efficiency, etc. Likewise, the proposed UVCR control scheme reduces the complex dual-transformations and mathematical analysis, high delayed signals for generation of reference current/voltage signals to drive the 5-level DCMLI-MDUPQC device. The performance evaluation of proposed UVCR controlled 5-level DCMLI-MDUPQC topology is verified through MATLAB/Simulink computational tool and simulation results are presented complying with IEEE-519 standards to attain good compensation features. The further work can be carried on reduced-switch multilevel inverter of MD-UPQC device for getting good compensation features with fewer switching elements.

\section{REFERENCES}

[1] L. Zhu, S. Chen, W. Mo, Y. Wang, G. Li and G. Chen, "Integrated Power Flow Solution for Interconnected Transmission and Distribution Network," IEEE 3rd International Electrical and Energy Conference (CIEEC), 2019, pp. 1076-1080, doi: 10.1109/CIEEC47146.2019.CIEEC-2019398.

[2] L. F. de O. Costa and J. M. de C. Filho, "Electrical Power Quality and the Challenges Faced by Power Assemblies Applications in Petrochemical Industry," IEEE Transactions on Industry Applications, vol. 52, no. 5, pp. 4495-4502, Sept.-Oct. 2016, doi: 10.1109/TIA.2016.2573258.

[3] A. Agarwal, S. Kumar and S. Ali, “A Research Review of Power Quality Problems in Electrical Power System,” MIT International Journal of Electrical and Instrumentation Engineering, vol. 2, no. 2, pp. 88-93, 2012.

[4] G. S. Chawda, A. G. Shaik, O. P. Mahela, S. Padmanaban and J. B. Holm-Nielsen, "Comprehensive Review of Distributed FACTS Control Algorithms for Power Quality Enhancement in Utility Grid With Renewable Energy Penetration,” IEEE Access, vol. 8, pp. 107614-107634, 2020, doi: 10.1109/ACCESS.2020.3000931.

[5] A. Ghosh and G. Ledwich, "Power Quality Enhancement Using Custom Power Devices," Kluwer Academic Publishers, United States America (USA), 2002.

[6] R. Nittala, A. M. Parimi and K. U. Rao, "Comparing the performance of IDVR for mitigating voltage sag and harmonics with VSI and CSI as its building blocks," IEEE International Conference on Signal Processing, Informatics, Communication and Energy Systems (SPICES), 2015, pp. 1-5, doi: 10.1109/SPICES.2015.7091365.

[7] S. Sreejith, S. P. Simon and M. P. Selvan, "Investigations on power flow solutions using Interline Power Flow Controller (IPFC)," International Conference on Sustainable Energy and Intelligent Systems (SEISCON 2011), 2011, pp. 63-68, doi: 10.1049/cp.2011.0336.

[8] G. Mythily and S. V. R. L. Kumari, "Power Quality Improvement by IUPQC," International Conference on Inventive Research in Computing Applications (ICIRCA), 2018, pp. 1280-1285, doi: 10.1109/ICIRCA.2018.8597191.

[9] P. V. Naidu and B. B. Raja, "A new proposal for voltage regulation multi feeders/Multibus systems using MC-DVR," International Conference on Power and Energy Systems, 2011, pp. 1-8, doi: 10.1109/ICPES.2011.6156679.

[10] S. M. Mukassir, S. M. M. Mudassir, S. Sultana and D. Giribabu, "The new trend in power conditioning using multi-converter unified power-quality conditioning (MC-UPQC) for multi feeder system," International Conference on Energy, Communication, Data Analytics and Soft Computing (ICECDS), 2017, pp. 3356-3361, doi: 10.1109/ICECDS.2017.8390081.

[11] N. S. Rao and P.V. R. Rao, "Performance Analysis of Multi-Feeder Distribution System Using MP-UPQC Device under Various Load Conditions," Journal of Advanced Research in Dynamical \& Control Systems, vol. 12, no. 2, pp.2130-2141, 2018, doi: 10.5373/JARDCS/V12I2/S20201258.

[12] A. K. Yadav, P. Tiwari and R. Maurya, "Power Quality Conditioning in multifeeder using MC-UPQC," International Conference on Electrical and Electronics Engineering (ICE3), 2020, pp. 645-649, doi: 10.1109/ICE348803.2020.9122992.

[13] J. G. Subarnan, "Multilevel inverters: An enabling technology," Hybrid-Renewable Energy Systems in Microgrids; Elsevier: Amsterdam, The Netherlands, pp. 61-80, 2018, doi: 10.1016/B978-0-08-102493-5.00004-2.

[14] H. A. Rub, M. Malinowski and K. Al-Haddad, "Multilevel Converter/Inverter Topologies and Applications," Power Electronics for Renewable Energy Systems, Transportation and Industrial Applications, 2014, pp.422-462, doi: 10.1002/9781118755525.ch14.

[15] H. Akagi, "Multilevel Converters: Fundamental Circuits and Systems," Proceedings of the IEEE, vol. 105, no. 11, pp. 2048-2065, 2017, doi: 10.1109/JPROC.2017.2682105.

[16] A. Krishna R and L. P. Suresh, “A brief review on multi level inverter topologies," International Conference on Circuit, Power and Computing Technologies (ICCPCT), 2016, pp. 1-6, doi: 10.1109/ICCPCT.2016.7530373.

[17] M. Tamasas, M. Saleh, M. Shaker and A. Hammoda, "Evaluation of modulation techniques for 5-level inverter based on multicarrier level shift PWM," MELECON 2014 17th IEEE Mediterranean Electrotechnical Conference, 2014, pp. 17-23, doi: 10.1109/MELCON.2014.6820499.

[18] R. S. Yallamilli and M. K. Mishra, "Instantaneous Symmetrical Component Theory Based Parallel Grid Side Converter Control Strategy for Microgrid Power Management," IEEE Transactions on Sustainable Energy, vol. 10, no. 2, pp. 682-692, 2019, doi: 10.1109/TSTE.2018.2845469.

[19] K. Palanisamy, J. Sukumar Mishra, I. J. Raglend and D. P. Kothari, "Instantaneous power theory based Unified Power Quality Conditioner (UPQC)," Joint International Conference on Power Electronics, Drives and Energy Systems \& 2010 Power India, 2010, pp. 1-5, doi: 10.1109/PEDES.2010.5712453.

[20] M. Kesler and E. Ozdemir, "Synchronous-Reference-Frame-Based Control Method for UPQC Under Unbalanced and Distorted Load Conditions," IEEE Transactions on Industrial Electronics, vol. 58, no. 9, pp. 3967-3975, 2011, doi: 10.1109/TIE.2010.2100330.

[21] N. S. Rao and P.V. R. Rao, "Power Quality Enhancement in Multi-Feeder Distribution System Using MF-UPQC Device," International Journal of Recent Technology and Engineering, vol. 8, no.2, pp.6092-6088, 2019, doi: 10.35940/ijrte.B3808.078219.

[22] J. V. R. Babu and M. K. Kumar, "Multilevel diode clamped D-Statcom for power quality improvement in distribution systems," 
International Journal of Power Electronics and Drive System (IJPEDS), vol. 12, no.1, pp.217-227, 2021, doi: 10.11591/ijpeds.v12.i1.pp217-227.

[23] D. Djoudi, B. Cherif, T. Toufik and O. Abdelkhalek, "Hybrid unified power quality conditioner for powerquality enhancement," International Journal of Power Electronics and Drive System (IJPEDS), vol. 11, no.4, pp.2126-2134, 2020, doi:10.11591/ijpeds.v11.i4.pp2126-2134.

[24] G. Satyanarayana, K. N. V. Prasad, G. R. Kumar and K. L. Ganesh, "Improvement of power quality by using hybrid fuzzy controlled based IPQC at various load conditions," International Conference on Energy Efficient Technologies for Sustainability, 2013, pp. 1243-1250, doi: 10.1109/ICEETS.2013.6533565.

[25] K. L. Ganesh, N. S. Naik, K. Narendra and G. S. Narayana, "A Newly Designed Asymmetrical Multi-Cell Cascaded Multilevel Inverter for Distributed Renewable Energy Resources," International Journal of Recent Technology and Engineering, vol. 7, no. ICETESM, pp. 248-255, 2019.

\section{BIOGRAPHIES OF AUTHORS}

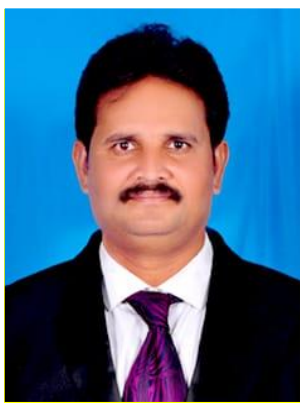

Naarisetti Srinivasa Rao (D) SC P was born in 1974. He received the B.E degree in Electrical and Electronics Engineering from Andhra University, Visakhapatnam, India in 1999 and M.Tech degree from JNTUCEA, Anantapur, India in 2007. He is currently pursuing a Ph.D degree in Electrical and Electronics Engineering Department at University college of Engineering and Technology, Acharya Nagarjuna University, Andhra Pradesh, India. Currently working at University of Technology and Applied Sciences-IBRI, Sultanate of Oman. His research interests are in the field of Power Systems, Power-Quality, FACTS, Renewable Energy Sources, Power-Electronic Converters, Advanced Control Systems and Artificial Intelligence. He can be contacted at email: nsrinivasarao.eee@gmail.com.

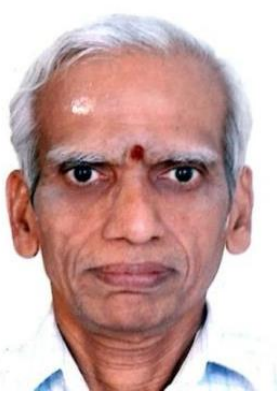

Pulipaka Venkata Ramana Rao (D) SC P S was born in India in 1946; He received the B.Tech degree in Electrical and Electronics Engineering from IIT Madras, India in 1967 and M.Tech degree from IIT Kharagpur, India in 1969. He received Ph.D from R.E.C Warangal in 1980. Total teaching experience 41 years at NIT Warangal out of which 12 years as Professor of Electrical Department. Currently Professor of Electrical Department in University college of Engineering and Technology, Acharya Nagarjuna University, Andhra Pradesh, India. His fields of interests are Power system operation and control, Power System Stability, HVDC and FACTS, Power System Protection, Application of DSP techniques and Application of Intelligent control techniques to Power systems. He can be contacted at email: pvr_eee@yahoo.co.in. 